\title{
“UM VOTO QUALQUER"? \\ O Papel do Ministro Relator na Deliberação no SUPREMO TRIBUNAL FEDERAL*
}

VIRGÍLIO AFONSO DA SILVA ${ }^{\dagger}$

RESUMO: No Supremo Tribunal Federal, o papel do ministro relator não foi ainda objeto de estudo mais detido. A percepção mais difundida é a de que o ministro relator, por ser o ministro que mais se ocupa do caso, teria papel preponderante. Estatísticas mostram que o relator costuma ser seguido na esmagadora maioria das decisões do STF. Mas, para além dos números, pouco se sabe qual é a influência do relator e de seu voto no processo de deliberação nos casos mais polêmicos, que chamam mais a atenção tanto da comunidade jurídica quanto do grande público e da imprensa. Na medida em que nesses casos - ao contrário do que ocorre normalmente - todos os ministros costumam levar seus votos prontos para a sessão de julgamento, é possível supor que o papel e o grau de influência do relator seja diferente do usual. Este artigo é parte dos resultados de uma pesquisa que pretende compreender o que os próprios ministros do STF pensam da prática deliberativa e decisória desse tribunal.

PALAVRAS-ChAVE: Ministro Relator; Deliberação; Supremo Tribunal Federal.

\footnotetext{
* A pesquisa que deu origem a este artigo teve financiamento da Fundação de Amparo à Pesquisa do Estado de São Paulo (processo FAPESP 2011/01066-0). Partes do resultado da pesquisa foram apresentados e discutidos no Seminário de Pesquisa que organizo em conjunto com os professores Conrado Hübner Mendes e Marcos Paulo Verissimo na Faculdade de Direito da USP. Agradeço aos participantes os comentários que ajudaram a melhorar o texto. Gostaria também de agradecer a Guilherme Benages Alcantara e Tatiana Alvim a hospitalidade em Brasília durante às minhas visitas ao Supremo Tribunal Federal.

${ }^{\dagger}$ Professor Titular de Direito Constitucional na Faculdade de Direito da Universidade de São Paulo, Brasil.
} 
ABSTRACT: The role of the Justice rapporteur in the Brazilian Supreme Court still has not been subject of great scholarly attention. The most widespread view is that the Justice rapporteur has a prominent role, because he or she is the Justice who most intensively studies the case. Statistics show that the other ten Justices tend to follow the written opinion of the Justice rapporteur in almost every case. Beyond the numbers, however, the actual influence of the rapporteur's opinion on the deliberation is unclear when the case attracts more attention of the legal community, as well as of the society as a whole and the media. Inasmuch in those cases - contrary to what usually occurs - every Justice uses to bring a written opinion to the deliberation session, it is possible for the role and the influence of the Justice rapporteur to be different than it usually is. This article presents parts of the results of a broader research aiming at grasping what the Justices of the Brazilian Supreme Court themselves think of the deliberation and decision-making process within that court.

KEYWORDS: Judge Rapporteur; Deliberation; Brazilian Supreme Court. 


\section{SUMÁRIO:}

I. INTRODUÇÃO.................................................................................................183

II. A PESQUISA E SUA METODOLOGIA ..................................................185

III. O PAPEL do RELATOR, de SEU RELATÓRIO E dE SEU VOTO ............188

IV. Votos REDIGIDOS COM ANTECEDÊNCIA E O PAPEL DO

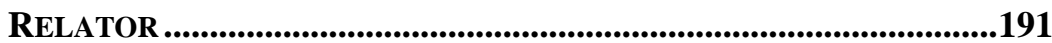

V. O VOTO QUASE SECRETO DO MINISTRO RELATOR .........................193

VI. A POSTURA do Relator EM RELAÇão a ARgumentos

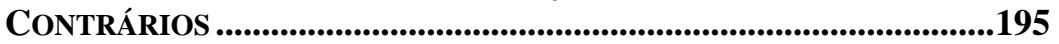

VII. O RELATOR PARA O ACÓRDÃO ................................................197

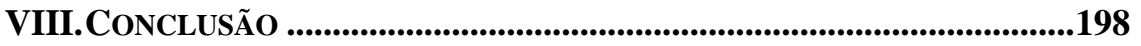

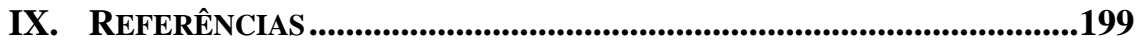

\section{TABLE OF CONTENTS:}

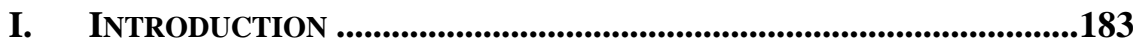

II. THE RESEARCH AND ITS METHODOLOGY ......................................185

III. THE ROLE OF THE RAPPORTEUR, HIS REPORT AND HIS OPINION .188

IV. OPINIONS WRITTEN IN ADVANCE AND THE ROLE OF THE JUSTICE

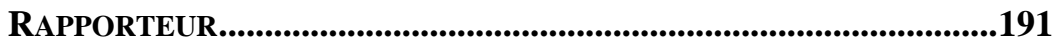

V. THE ALMOST SECRET OPINION OF THE JUDGE RAPPORTEUR........193

VI. THE RAPPORTEUR'S ATTITUDE VIS-À-VIS OPPOSING

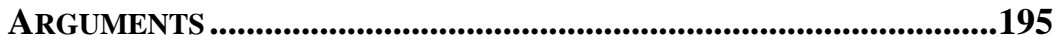

VII. THE RAPPORTEUR FOR THE HOLDING ..............................................197

VIII.CONCLUSION ……...............................................................................................198

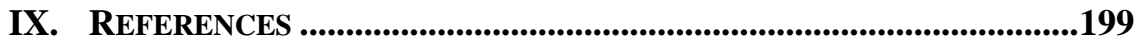




\section{INTRODUÇÃO}

Os processos deliberativo e decisório em tribunais constitucionais e supremas cortes podem variar bastante: as sessões podem ser públicas ou reservadas, votos divergentes podem ser permitidos ou proibidos, a decisão pode ser per curiam ou seriatim, pode haver discricionariedade nas escolha de casos ou não, dentre outras variáveis. Diante desse cenário tão diversificado, uma das maiores constantes é a existência de um juiz relator para cada caso a ser decidido por esses tribunais. É claro que há variação no critério de escolha do juiz relator - sorteio, escolha pelo presidente, especialização - mas a existência de um juiz encarregado de relatar cada caso parece ser natural para quase todos os tribunais constitucionais e supremas cortes. ${ }^{1}$

Diante dessa constatação, é surpreendente que haja tão poucos estudos sobre o papel dos juízes relatores nos processos deliberativo e decisório desses tribunais. ${ }^{2}$ Pouco se sabe - para usar o título de um dos poucos artigos especificamente dedicados ao tema - se o juiz relator é "o senhor do processo ou apenas um dentre oito"3 (ou nove, ou onze, ou quinze, dependendo do tamanho do tribunal).

\footnotetext{
${ }^{1}$ Além do critério de escolha do relator, uma segunda variação possível é o momento em que se define quem será o relator. Ainda que, em geral, a definição do relator seja um dos primeiros atos do processo decisório, em algumas cortes o relator é definido somente após uma primeira rodada de deliberação. Nesse caso, o relator já passa a ser o redator da opinião da corte. Esse é o modelo adotado na Suprema Corte dos Estados Unidos.

${ }^{2}$ Há, contudo, farta literatura sobre o papel redator da opinião da corte na Suprema Corte dos Estados Unidos. Cf., por exemplo, SPRIGGS II, J.F.; MALTZMAN, F.; WAHLBECK, P.J. Bargaining on the U.S. Supreme Court: Justices' Responses to Majority Opinion Drafts. The Journal of Politics, Vol. 61, 2, 1999.

${ }^{3}$ KRANENPOHL, U. Herr des Verfahrens oder nur Einer unter Acht? Der Einfluss des Berichterstatters in der Rechtsprechungspraxis des Bundesverfassungsgerichts. Zeitschrift für Rechtssoziologie, Vol. 30, 2, 2009. Há alguns estudos dedicados ao papel do relator, mas a partir de outros pontos de vista que não o seu papel na deliberação. Cf., por exemplo, GAROUPA, N.; GILI, M.; GÓMEZ-POMAR, F. Political Influence and Career Judges: An Empirical Analysis of Administrative Review by the Spanish Supreme Court. Journal of Empirical Legal Studies, Vol. 9, 4, 2012; e PELLEGRINA, L.D.; GAROUPA, N. Choosing between the government and the regions: An empirical analysis of the Italian constitutional court decisions. European
} Journal of Political Research, Vol. 52, 4, 2013. Ambos os artigos procuram analisar as 
No Supremo Tribunal Federal, o papel do ministro relator também não foi ainda objeto de estudo mais detido. ${ }^{4} \mathrm{~A}$ percepção mais difundida é a de que o ministro relator estaria mais para "senhor do processo" do que "apenas um dentre onze", já que é o ministro que mais se ocupa com o caso. Mais do que isso, estatísticas mostram que o relator costuma ser seguido na esmagadora maioria das decisões do STF. ${ }^{5}$ Mas, como será explicado mais adiante, apesar dessa clara estatística, pouco se sabe qual é a influência do relator e de seu voto no processo de deliberação nos casos mais polêmicos, que chamam mais a atenção tanto da comunidade jurídica quanto do grande público e da imprensa. Na medida em que nesses casos - ao contrário do que ocorre normalmente - todos os ministros costumam levar seus votos prontos para a sessão de julgamento, é possível supor que o papel e o grau de influência do relator sejam diferentes se comparados com o cenário usual em que os demais ministros chegam à sessão de julgamento com informações muito superficiais sobre o que vai ser julgado.

Este texto expõe parte dos resultados de uma pesquisa mais ampla, que tem como escopo compreender o que os próprios ministros pensam das práticas deliberativa e decisória do STF. No caso específico do papel do relator, procurou-se indagar (1) como os ministros avaliam de forma

ligações entre a afiliação política do relator e as chances de sucesso de demandas de interesse do governo na Itália e na Espanha.

${ }^{4}$ Dediquei alguns parágrafos sobre esse tema em artigo recente: Cf. SILVA, V.A. da. Deciding Without Deliberating. International Journal of Constitutional Law, Vol. 11, 3, 2013, p. 569-570. Há, ainda, alguns estudos recentes, de caráter quantitativo, acerca da correlação entre o voto do relator e o resultado final das decisões do STF (especialmente nas ADIs). Sobre isso, cf. nota de rodapé 5, a seguir.

${ }^{5}$ Cf., por exemplo, OLIVEIRA, F.L. de. Supremo Relator: processo decisório e mudanças na composição do STF nos governos FHC e Lula. Revista Brasileira de Ciências Sociais, Vol. 27, 80, 2012. Cf. também OLIVEIRA, F.L. de. Processo decisório no Supremo Tribunal Federal: coalizões e "panelinhas". Revista de Sociologia e Política, Vol. 20, 44, 2012, p. 148: "em 98\% dos casos não unânimes [em ADIs], o voto do relator foi o voto da maioria do tribunal". Para uma crítica, baseada em modelos probabilísticos, à ideia de um "supremo relator", Cf. DUARTE, G.; FREIRE, D.; MARTINS, R. Revisitando o Supremo Relator: Teorias e Modelos Explicativos. V Seminário Discente do Programa de Pós-Graduação em Ciência Política, 2 de maio de 2015. São Paulo: Faculdade de Filosofia, Letras e Ciências Humanas da Universidade de São Paulo, 2015. Disponível em:

$<$ http://www.sistemas.fflch.usp.br/ocspkp/sdpscp/Vsem/paper/view/402>. Acesso em: 3 de janeiro de 2016. 
geral esse papel, (2) qual é a relevância do recente hábito de os ministros levarem seus votos já redigidos para as sessões de julgamento dos casos mais polêmicos, (3) se o fato de o voto do relator não ser distribuído com antecedência tem algum efeito no seu poder de influência, (4) se os ministros entendem que o voto do relator deve incorporar apenas os argumentos que subsidiam a opinião do próprio relator ou se ele deve expor um panorama mais amplo do tema em debate, e, por fim, (5) como os ministros veem a figura do "relator para o acórdão" nos casos em que o relator original fica vencido. A cada uma dessas questões é dedicado um tópico deste artigo. Antes, contudo, faço uma pequena explicação sobre a pesquisa no âmbito da qual este texto se insere, especialmente de seus objetivos mais gerais e de sua metodologia.

\section{A Pesquisa e sua Metodologia}

Como dito acima, este artigo é parte dos resultados de uma pesquisa mais ampla, sobre a prática deliberativa no Supremo Tribunal Federal. Essa pesquisa baseou-se sobretudo em entrevistas com ministros do STF. Essas entrevistas não tinham o objetivo de saber o que se passa no interior da sala de julgamento, já que as sessões do STF são públicas e suas sessões plenárias, transmitidas ao vivo. As entrevistas tinham como objetivo compreender como os próprios ministros do STF encaram o processo deliberativo do qual participam.

Como a forma de deliberação e decisão no STF é a mesma há décadas, cada novo ministro se vê, sem grandes possibilidades de variação, compelido a seguir o rito deliberativo ditado pela tradição e pelo regimento interno. Isso não significa, contudo, que todos os ministros encaram seu papel individual em uma instituição coletiva como o Supremo Tribunal Federal da mesma forma. Em outras palavras: as informações a que temos acesso por meio da extrema publicidade a que estão submetidas as atividades dos ministros do STF não são suficientes para compreender o papel que os próprios ministros pretendem desempenhar, tampouco nos dizem o que cada ministro pensa da atual forma de decisão nesse tribunal. Não é factível supor que todos os ministros tenham a mesma compreensão sobre o papel da colegialidade, dos votos divergentes, sobre a função do relator, sobre a importância de um pedido de vista, ou sobre os efeitos da extrema publicidade na prática deliberativa do STF.

Essa parece ser uma lacuna na produção acadêmica sobre o Supremo Tribunal Federal. De um lado, temos acesso a uma quantidade cada vez maior de informações (via banco de dados na internet, TV Justiça, canal 
do STF no YouTube e até mesmo no Twitter), de outro, nem sempre sabemos o que aqueles que produzem essas informações (os ministros e ministras) pensam sobre a forma como elas são produzidas. As entrevistas tinham como função fornecer subsídios para conhecer melhor a prática deliberativa do STF a partir de um material não disponível até então.

Todas as entrevistas foram gravadas e depois transcritas. Antes de iniciar cada entrevista, foi assegurado ao entrevistado que as informações seriam usadas de forma anônima. Como o objetivo da pesquisa não é expor a opinião individual dos ministros, mas construir um cenário coletivo a partir de visões individuais, o anonimato nas declarações não compromete os resultados. Pelo contrário, ele tem o potencial de deixar os ministros à vontade para expor de forma mais sincera suas opiniões. ${ }^{6}$

Para manter o anonimato, os nomes dos ministros foram substituídos por letras. Embora não haja nenhuma ordem reconhecível nessas letras, uma divisão clara foi feita: as letras A a I representam ministros no exercício da função (no momento da entrevista), enquanto as letras $\mathrm{N}$ a U indicam ministros que, ao tempo das entrevistas, já estavam aposentados. Ao longo do texto, não faço distinção entre ministros e antigos ministros, a não ser nos casos em que isso tenha me parecido conveniente, para deixar alguma contraposição mais clara. De qualquer forma, é sempre possível saber se se trata de um antigo ministro ou de um ministro atual com base nas letras.

Como regra geral, a despeito de suas agendas congestionadas, os ministros foram extremamente receptivos aos objetivos da pesquisa. Em vários casos, dispuseram-se até mesmo a fazer mais de um encontro para que as entrevistas pudessem ser feitas no ritmo ideal. Como foram poucos os ministros que se recusaram a conversar, é possível supor que os resultados obtidos têm um grande potencial explicativo sobre a prática deliberativa no Supremo Tribunal Federal. ${ }^{7}$

${ }^{6}$ Essa metodologia foi inspirada na metodologia usada por Uwe Kranenpohl em trabalho sobre o Tribunal Constitucional alemão. Cf. KRANENPOHL, U. Hinter dem Schleier des Beratungsgeheimnisses. Wiesbaden: VS Verlag für Sozialwissenschaften, 2010.

${ }^{7}$ Dentre os ministros e ministras que estavam no exercício de sua função durante a realização da pesquisa, apenas 4 se recusaram, apesar das inúmeras tentativas, a conceder entrevistas: Celso de Mello, Joaquim Barbosa, Cármen Lúcia Antunes Rocha e Rosa Weber. 
Este e os outros artigos que expõem os resultados da pesquisa - todos publicados ou a serem publicados em revistas de acesso livre ${ }^{8}$ - não têm o perfil tradicional de um artigo acadêmico na área jurídica. Não é objetivo deste texto nem defender normativamente uma tese sobre o processo deliberativo no Supremo Tribunal Federal, nem ser descritivo a partir de uma perspectiva exclusivamente externa, tampouco fazer uma revisão de literatura sobre o tema investigado. O que se pretende, como foi delineado acima, é fazer uma tentativa de algo que poderia ser chamado de descrição interna. E, da mesma forma que as decisões do STF são o produto de 11 opiniões distintas que, de alguma forma, têm que se encaixar em um produto final, essa tentativa de descrição interna da prática deliberativa do Supremo Tribunal Federal também tenta construir a imagem de uma instituição a partir das opiniões individuais de seus membros. Com a diferença de que, no caso desta pesquisa, não são apenas 11 os ministros que formam o panorama geral, mas $17 .{ }^{9}$

Contudo, apesar de ser um texto que procura em grande parte apresentar as opiniões dos ministros do Supremo Tribunal Federal sobre questões ligadas à deliberação no tribunal, isso não transforma o artigo em uma simples colagem de opiniões. De um lado, há uma sistematização dessas opiniões, classificando-as e salientando as concordâncias e divergências; de outro, por mais que não fosse objetivo da pesquisa tomar partido em relação aos temas debatidos, em alguns momentos foi necessário expor certas contradições presentes nos depoimentos ou ainda deixar explícitos eventuais problemas fáticos a eles ligados.

Uma última explicação sobre a pesquisa e as entrevistas é necessária: o objeto das conversas não era a atitude dos ministros em todas as dezenas de milhares de decisões anuais. $\mathrm{O}$ foco eram exclusivamente as decisões mais importantes, mais polêmicas, que chamam mais a atenção do público. Essa é uma explicação importante porque várias das afirmações sobre o papel do relator, sobre a quantidade de votos divergentes, sobre a dinâmica da deliberação, valem apenas para esses casos. Assim, para usar um exemplo relacionado ao papel do ministro

\footnotetext{
8 Embora não seja uma exigência da FAPESP, instituição que financiou a pesquisa, pareceu-me importante que os resultados da pesquisa, financiada com dinheiro público, ficassem disponíveis a todos, sem custo. Daí a opção por revistas de acesso aberto.

${ }_{9}^{9}$ Os ministros e ex-ministros entrevistados foram os seguintes: Ayres Britto, Carlos Velloso, Cézar Peluso, Dias Toffoli, Enrique Lewandowski, Eros Grau, Francisco Rezek, Gilmar Mendes, Ilmar Galvão, Luiz Fux, Marco Aurélio Mello, Moreira Alves, Nelson Jobim, Luís Roberto Barroso, Sepúlveda Pertence, Sydney Sanches e Teori Zavascki.
} 
relator, se é verdade que na grande maioria das decisões os demais ministros tendem a segui-lo sem grandes questionamentos, isso não necessariamente ocorre nas decisões mais relevantes, mais polêmicas e que chamam mais a atenção do público externo ao tribunal. Nessas, mesmo que o relator faça parte do grupo majoritário, isso não necessariamente significa que os demais ministros seguiram os seus argumentos. O mesmo vale para a prática de levar votos prontos para a sessão de julgamento; isso costuma acontecer apenas nas grandes decisões.

Assim, uma pesquisa estritamente quantitativa poderia mostrar um cenário diferente daquele que serviu de pano de fundo para a minha pesquisa. No entanto, a escolha do foco parece-me mesmo assim justificada. Se o que se quer analisar é o papel do Supremo Tribunal Federal como corte constitucional, seu papel na relação entre os poderes, então não faz sentido investigar como os ministros se comportam nas decisões das dezenas de milhares de agravos de instrumento, por exemplo. O que importa é a atitude dos ministros nas decisões que fazem parte do cotidiano de todos os tribunais constitucionais, como aquelas sobre reforma política, financiamento partidário, aborto, pesquisa em células-tronco, casamento de pessoas do mesmo sexo, ações afirmativas, drogas, etc. ${ }^{10}$

\section{O PAPEl do Relator, DE SEU RelatóRIo E DE SEU Voto}

Em geral, os ministros do STF veem o papel do relator como decisivo na deliberação. Esse papel é traduzido por expressões como "ele baliza todo o debate", 11 "é uma posição preponderante", 12 "ele fixa a moldura do debate",13 "é um ponto de partida para discussão". ${ }^{14}$ Mesmo assim, há vozes discordantes sobre esse papel preponderante e também indicações de outros papéis decisivos do relator.

Há ministros que relativizam o papel do relator. Uma causa citada é o

${ }^{10} \mathrm{O}$ texto deste tópico, que resume a metodologia e os objetivos da pesquisa sobre deliberação no STF, é repetido em todos os artigos que expõem os resultados dessa pesquisa.

${ }^{11} \mathrm{~B}$.

${ }^{12} \mathrm{~F}$.

${ }^{13} \mathrm{R}$.

${ }^{14} \mathrm{C}$. 
volume de trabalho no STF. ${ }^{15}$ Nesse sentido, o ministro C afirmou:

Na grande maioria dos casos, os ministros não leem o relatório, basicamente porque há muito serviço para ler, mas também pelo fato de que muitos relatórios são muito extensos [...]. Em outras palavras o relatório, na prática, acaba não exercendo a sua função.

Além disso, alguns ministros claramente diferenciam o papel do relator nos casos corriqueiros e nos casos que atraem a opinião pública. $\mathrm{O}$ ministro $\mathrm{P}$, por exemplo, salienta a necessidade de diferenciar entre os casos repetitivos e os casos marcantes, para concluir que apenas nos primeiros o papel do relator seria decisivo. De forma mais incisiva, o ministro T argumenta que, quando a matéria não chama atenção (ou, nas suas palavras, "não dá ibope"), o ministro relator tem papel decisivo, mas:

Quando a matéria 'dá ibope', então o voto do relator é tomado como um voto qualquer. Às vezes, dependendo de qual seja a composição, o fato de o relator ser fulano e não sicrano pode ensejar uma reação mais ou menos aguda de determinados outros ministros. ${ }^{16}$

\section{Essa última ressalva - quem é o relator - é também salientada pelo ministro Q:}

Há naturalmente uma condicionante [no papel desempenhado pelo relator]: quem é o relator e qual é a imagem que ele projeta no imaginário dos dez colegas naquele momento da história do tribunal.

Por fim, alguns ministros atribuíram funções adicionais ao relator que não simplesmente "balizar o debate". A principal delas seria o seu poder de agenda. Assim, o ministro F salienta o papel estratégico na definição de quando um caso deve entrar na pauta de julgamentos:

O relator administra a tese que ele tem sob julgamento com o tempo. Se ele for uma pessoa de visão tática, aí é uma questão não estritamente técnico-jurídica, mas que faz parte da formação do ser humano e também de quem chegou à Suprema Corte, de saber o seguinte: "olha esse não é o momento de eu levar tal tema". [...] Eu, por exemplo, eu não me surpreendi que o ministro Marco

${ }^{15}$ A menção ao volume de trabalho como obstáculo à deliberação mais qualificada foi uma constante em todas as entrevistas.

${ }^{16} \mathrm{~T}$. 
Aurélio não tenha trazido a anencefalia antes da aposentadoria do ministro Eros Grau.

A mesma ênfase foi dada pelo ministro E, que, além de simplesmente mencionar que o relator tem o poder de definir quando os processos sob sua relatoria devem ser liberados, explicitamente relaciona esse poder com a deliberação:

O relator tem um papel quase absoluto quanto à agenda, porque o processo só vai a julgamento a partir do momento em que ele resolva levar o processo a julgamento. [...] Esse é um poder grande de supressão da discussão. ${ }^{17}$

Após serem indagados de forma bastante geral sobre o papel do relator e de seu voto, os ministros foram provocados a refletir sobre os efeitos que algumas peculiaridades do modelo deliberativo e decisório do STF podem ter nesse papel. As principais dessas peculiaridades são (1) o fato de que, nos casos que atraem mais a atenção do público, todos os ministros tendem a levar seus votos já prontos para a sessão de julgamento e (2) o fato de os demais ministros não receberem o voto do relator com antecedência, ou seja, o fato de os demais ministros irem para a sessão de julgamento sem saber quais são a decisão e os argumentos do relator. Além disso, não parece haver consenso se o relator deveria expor opiniões contrárias às suas no seu voto ou se deve apenas defender a sua posição, ignorando os argumentos que não ajudem a sustentar a sua tese. Por fim, quando indagados sobre a figura do relator para o acórdão, os ministros não parecem ver nenhum problema na troca de relator quando o relator original fica vencido; pelo contrário, todos parecem assumir essa troca como uma necessidade incontornável. A possibilidade de outro arranjo, como manter o mesmo relator, ainda que sua tese inicial tenha sido derrotada, não é vista como positiva. Analisarei todos esses temas nos tópicos que seguem.

${ }^{17}$ Em sentido semelhante, sobre o poder de agenda do relator no Tribunal Constitucional alemão, Cf. KRANENPOHL, U. Herr des Verfahrens oder nur Einer unter Acht? Der Einfluss des Berichterstatters in der Rechtsprechungspraxis des Bundesverfassungsgerichts. Zeitschrift für Rechtssoziologie, Vol. 30, 2, 2009, p. 139. 


\section{Votos Redigidos CoM ANTECEDÊNCIA E O PAPEL DO RELATOR}

Nos grandes casos, os ministros têm sempre levado seus votos já redigidos para a sessão de julgamento. Em outro trabalho, sustentei que esse é um fator antideliberativo da atual prática decisória no STF. ${ }^{18}$ Além disso, essa prática tem o potencial de relativizar o papel do relator como o ministro que pauta o debate, já que o debate é pautado pelos votos já escritos. Vários ministros parecem ter opinião semelhante a essa. Outros, contudo, têm argumentos para justificar essa prática. Algo que ficou claro nas entrevistas, todavia, foi a nítida distinção entre a prática atual e a prática dos primeiros 10 ou 15 anos de vigência da Constituição de 1988. Os antigos ministros afirmam que raramente levavam seus votos prontos para as sessões. Essa mudança de comportamento pode ter várias razões. A primeira delas é a complexidade e, sobretudo, o impacto moral e social das causas que são hoje julgadas pelo STF, o que poderia exigir uma preparação prévia mais intensa e um documento escrito para ser lido no momento do debate. Uma segunda explicação, bastante corrente, o efeito da TV Justiça, será analisada em outro artigo.

Com relação aos efeitos antideliberativos da prática de levar votos prontos, especialmente em razão de uma menor disposição para mudar a posição já assentada no voto, cuja redação tomou tempo e esforço de cada ministro e de seus gabinetes, o ministro C é enfático:

Dificilmente um ministro vai reconsiderar, porque ele não espera os outros argumentos, ele já põe o ponto de vista dele e ele vai para lá para defender aquele ponto de vista a qualquer preço.

Essa visão é compartilhada por vários ministros, que argumentam que quem leva um voto pronto tende a "não querer refletir e querer brigar pelo seu voto", ${ }^{19}$ e que "o debate [acaba] sendo irrelevante, porque o sujeito já vem comprometido com uma linha". ${ }^{20}$ É interessante notar, contudo, que todos os ministros que fazem essas críticas também costumam levar seus votos prontos para a sessão de julgamento.

E a suscitada perda de preponderância do relator, mencionada acima e salientada pelas opiniões de alguns ministros, é também reforçada

${ }^{18}$ Cf. SILVA, V.A. da. Deciding Without Deliberating. International Journal of

Constitutional Law, Vol. 11, 3, 2013, p. 570.

$19 \mathrm{~F}$.

${ }^{20} \mathrm{R}$. 
explicitamente pelo ministro $\mathrm{G}$, que afirma que quando todos levam seus votos prontos, fica "mais difícil a modificação do seu voto, do seu entendimento, na medida em que cada membro componente do tribunal se prepara para votar como se relator fosse".

Alguns ministros, contudo, encaram com naturalidade a recente prática de ir com votos já redigidos para a sessão de julgamento. Alguns simplesmente afirmam que "quem leva voto escrito é porque está bem preparado"21 ou "fez uma pesquisa mais aprofundada",22 sem atribuir à prática nenhum efeito, como se ela fosse apenas o resultado neutro de um estudo mais detido sobre uma determinada matéria.

Um pouco mais nuançada é a justificativa do ministro E, que faz uma relação entre a necessidade ou conveniência de se levar o voto pronto e a posição que cada ministro ocupa na ordem de leitura:

\begin{abstract}
Preparar o voto é importante em certos casos porque, para concordar com o relator é muito fácil, você precisa estar mais preparado é na eventualidade de divergir. [...] Pelo menos o primeiro, o mais jovem, tem que estar preparado para votar, inclusive porque ele não sabe em que sentido vai votar o relator. Eu acho que na medida em que vai se distanciando do relator e chegando mais perto do decano, a preparação do voto é menos importante.
\end{abstract}

Como já foi mencionado acima, os ministros que já deixaram o tribunal há mais tempo tendem a estranhar a prática atual de levar votos prontos. O ministro $\mathrm{O}$, por exemplo, afirmou que levar votos já redigidos "não era comum; pelo menos até a minha aposentadoria isso não era comum no Supremo Tribunal Federal" e, em sentido idêntico, o ministro S: "ao tempo da composição que eu integrava era exatamente o contrário: preparava o voto apenas o relator e alguns dos participantes do julgamento traziam anotações". De forma irônica, o ministro P, em primeiro lugar, afirmou que "é claro que a hipótese de todos os ministros trazerem votos escritos é mais do que errada". Ao ser questionado sobre as diferenças, nesse aspecto, entre a prática atual e a prática da composição da qual participou, o ministro afirmou que a hipótese considerada por ele como "mais do que errada" tem ficado cada vez mais frequente, e conclui: "sobre células tronco ou aborto anencefálico, por exemplo, foi um confessionário de onze..."

Como não é possível proibir que os ministros levem seus votos prontos, alguns ministros têm sugerido que se limite o tempo de fala de

${ }^{21} \mathrm{D}$.

${ }^{22} \mathrm{I}$. 
cada um:

Para mim, o ideal seria o seguinte: juízes e partes teriam o mesmo prazo para deliberar. $\mathrm{O}$ advogado tem quinze minutos e o juiz tem quinze minutos. Eu acho até que, para concordar, não precisa de quinze minutos; [apenas] para discordar precisaria de quinze minutos. ${ }^{23}$

No mesmo sentido foi a declaração do antigo ministro P:

Eu creio razoável a proposta do Luís Roberto Barroso de dar um prazo para o voto. Isso obrigaria um certo poder de síntese. [Ninguém poderia ficar] lendo o voto, nem lembrando de João Sem Terra...

\section{O Voto Quase SeCreto do Ministro Relator}

Talvez uma das prática mais peculiares do Supremo Tribunal Federal seja o segredo em relação ao voto do relator. Não parece fazer sentido que os ministros cheguem no momento de decidir sem saber a opinião daquele que mais intensamente se ocupou do caso a ser decidido, o ministro relator. ${ }^{24}$

Nesse ponto, parece haver uma convergência entre os ministros, no sentido de que receber o voto do relator seria proveitoso, e isso por várias razões. Em primeiro lugar, e talvez como razão mais citada, haveria um enorme ganho de tempo, um efeito extremamente relevante em um tribunal assoberbado de casos a julgar. Vários ministros mencionaram esse efeito positivo. De forma mais detalhada, o ministro B afirma que, se o relator enviasse seu voto com antecedência, haveria uma clara "economia de tempo, também porque, se houvesse concordância, não haveria necessidade de tanta extensão e às vezes de tanto debate prévio".

É interessante notar, contudo, que os argumentos "tempo" e "excesso de trabalho" foram usados por um dos ministros em sentido oposto ao mencionado acima. Segundo o ministro N, receber o voto do relator com antecedência não ajudaria muito:

${ }^{23} \mathrm{G}$. É preciso ressaltar, contudo, que, mesmo afirmando um limite de 15 minutos como ideal, o ministro $G$, nos seus pronunciamentos, não se pauta necessariamente por esse limite

${ }^{24}$ Nesse sentido, Cf. SILVA, V.A. da. Deciding Without Deliberating. International Journal of Constitutional Law, Vol. 11, 3, 2013, p. 570. 
porque a carga de trabalho [...] é incrível, só quem está lá sabe; então, se eu tenho os meus processos e estou às voltas com os meus processos, eu não vou ter tempo de ler voto de ninguém antes da hora. Imagina se todos eles mandassem os votos, então eu ia passar a noite inteira lendo [...], não teria tempo. Então eu acho que é contraproducente [...] essa entrega do voto.

De qualquer forma, caso o ministro relator passasse a divulgar seu voto com antecedência aos outros ministros, a prática de levar votos prontos para o debate, tratada no tópico anterior, poderia ou deveria ser revista. Como salientado pelo ministro $B$, aquele que já sabe que sua opinião é semelhante à do relator não precisaria dispender tempo escasso na redação de um voto escrito. Essa conclusão vale sobretudo para a relação estabelecida pelo ministro E, mencionada acima, segundo a qual os ministros mais jovens, por serem os primeiros a votar, se sentiriam mais pressionados a levar votos prontos, porque teriam que estar preparados para não serem pegos de surpresa pelo voto do relator, especialmente no caso de terem opinião diversa. Também o antigo ministro U, embora não seja favorável à divulgação do voto do relator, afirma que, se isso ocorresse, seria mais fácil preparar um voto divergente.

Mas a divulgação do voto do relator, mesmo que desejada por boa parte dos ministros, ainda suscita alguns receios. Boa parte desses receios, contudo, não tem razões institucionais, mas pessoais, de imagem dos próprios ministros, que não querem correr o risco de divulgar seus argumentos com antecedência, para que outros ministros não possam elaborar contra-argumentos mais robustos. Assim, por exemplo, o ministro I afirma que, embora às vezes distribua seu voto como relator para alguns ministros mais próximos, "não faço com todos porque hoje, com essa exposição muito exacerbada que nós temos, você corre o risco do colega pegar um argumento seu e elaborar em cima desse argumento e levar você à lona".

Se esse receio soa impregnado de vaidade e individualismo, ele parece refletir com clareza a forma como alguns ministros veem seu papel na deliberação. Nesse sentido, o ministro T afirma:

se eu [...] recebesse os votos dos ministros $a, b$ e $c$ e [...] tivesse alguma dúvida, eu telefonaria [para os autores dos votos]. Agora se se tratasse do ministro $f$, eu ia aproveitar para cair em cima dele, fazer uma grande discussão, 
transformar aquilo num debate para tentar mostrar que eu sei Direito mais do que ele. ${ }^{25}$

Os poucos ministros que são contrários à ideia de que o relator possa ou deva distribuir seu voto com antecedência são aqueles ou que entendem que isso pode levar muitos ministros a acompanhar o relator por simples inércia, ${ }^{26}$ ou que entendem que o grau de influência do relator poderia ser potencializado, ${ }^{27}$ ou ainda que supõem que o julgamento já estaria decidido antes de se iniciar a sessão, antes de se ouvirem os advogados em suas sustentações orais, quando fosse o caso. ${ }^{28}$ Esse receio, contudo, não leva em consideração a possibilidade de que primeiro sejam ouvidas as sustentações orais de advogados, procuradores e outros participantes para que, em sessão distinta, o relator apresente seu voto e haja deliberação. Esse é, de resto, o modelo mais comum em tribunais constitucionais e supremas cortes. ${ }^{29}$

\section{A Postura do Relator em Relação a Argumentos CONTRÁRIOS}

O papel do relator como fornecedor de subsídios para um debate franco poderia supor um dever de que ele exponha, com a maior isenção possível, os principais argumentos envolvidos, ainda que, ao final, ele opte por uma das decisões possíveis e pelos argumentos que a sustentem.

\footnotetext{
${ }^{25}$ A menção, nesse trecho, aos ministros $a, b, c$ e $f$ foi feita pelo próprio ministro e não guardam relação com as letras usadas neste trabalho para fins de anonimização.

${ }^{26}$ Q. Há trabalhos acadêmicos que já se ocuparam dessa possibilidade (concordar com o relator por pura inércia, ou para maximizar o tempo livre). Cf., por todos, POSNER, R.A. What Do Judges and Justices Maximize? (The Same Thing Everybody Else Does). Supreme Court Economic Review, Vol. 3, 1, 1993.

${ }^{27} \mathrm{~A}$.

${ }^{28} \mathrm{~S}$.

${ }^{29}$ Em outra parte da pesquisa, que não é objeto deste artigo, sobre interação entre ministros e advogados, o ministro E sugeriu a adoção justamente dessa prática mais difundida em tribunais de outros países: "Eu acho que a sustentação oral do jeito que é feita no Brasil tem uma valia limitada, porque é um processo muito unilateral. $O$ relator geralmente já tem o seu voto pronto, de modo que, para o relator, a sustentação oral raramente produz alguma consequência. Eu seria até mesmo favorável a um modelo em que a sustentação oral se fizesse em sessão diversa da de julgamento, anteriormente à de julgamento".
} 
Caso contrário, isto é, caso o relator exponha apenas os argumentos que sustentem sua tese e esconda os argumentos a ela contrários, seu papel privilegiado na deliberação diminuiria e ele seria apenas o ministro que defende uma posição pessoal em primeiro lugar. ${ }^{30}$

Contudo, na percepção dos ministros, mesmo daqueles poucos que entendem que o relator deveria expor todos os lados do debate, a prática corriqueira no STF é justamente a do ministro relator que fala antes, mas não necessariamente de forma mais qualificada e mais interessada no debate. Seja porque "a condição humana é forte, você tende a defender o seu ponto de vista", 31 seja porque se entende que "uma decisão judicial se assemelha mais a uma decisão política do que uma discussão acadêmica", 32 a percepção dominante é a de que "são raros os momentos em que isso [a exposição de argumentos contrários] ocorre",,33 de que "normalmente nós procuramos construir o nosso voto com a doutrina que chancela o nosso entendimento; dificilmente nós levamos correntes diferentes", 34 enfim, de que suscitar o debate franco, simplesmente "não é a regra". 35

Talvez a opinião do ministro $U$ seja ilustrativa da postura dos relatores no STF: segundo ele, cabe ao relator defender seu ponto de vista, e a divulgação de teses contrárias, quando ocorre, não tem como objetivo fornecer subsídios para um debate franco, mas aumentar o poder persuasivo do voto do relator, que poderia ficar incompleto se deixasse

${ }^{30}$ Sobre o dever moral de o relator expor todos os pontos de vista, Cf. as opiniões de diversos juízes do Tribunal Constitucional alemão em KRANENPOHL, U. Herr des Verfahrens oder nur Einer unter Acht? Der Einfluss des Berichterstatters in der Rechtsprechungspraxis des Bundesverfassungsgerichts. Zeitschrift für

Rechtssoziologie, Vol. 30, 2, 2009, p. 147: "Em seu voto, o relator não poderia, por exemplo, esconder posições contrárias [...]. Isso não dá! [...] Ou seja, eu não posso ir para a sessão de deliberação e esconder um artigo acadêmico com opiniões contrárias. Isso seria absolutamente fatal! Ninguém faria isso."

${ }^{31} \mathrm{H}$.

$32 \mathrm{I}$.

${ }^{33} \mathrm{~F}$.

${ }^{34} \mathrm{G}$.

${ }^{35}$ P. O mesmo ministro P faz menção ao Min. Celso de Mello como alguém que tenderia a expor outros pontos de vista em seu voto como relator. A forma com que o Min. Celso de Mello o faz, contudo, não parece despertar a simpatia do ministro P: "eu diria que o rei do procedimento é obviamente o ministro Celso de Mello, né? [Ele] traz uma pesquisa quase escolar...". 
de abordar com antecedência - e rebater - os pontos de vistas contrários já conhecidos.

\section{O RELATOR PARA O ACÓRDÃo}

Por fim, um último aspecto relativo ao papel do relator diz respeito à figura do relator para o acórdão, quando o relator original tenha sido vencido. Nesse caso, sem qualquer exceção, todos os ministros defenderam a prática de troca de relator e não demonstraram ver nisso um sinal de um individualismo incompatível com a ideia de decisões proferidas pela instituição e não pelos seus ministros individualmente considerados. ${ }^{36}$

Ao serem confrontados com a prática de alguns tribunais constitucionais, ${ }^{37}$ nos quais o relator tem o dever de escrever a minuta da decisão final, não importa se concorda ou não com ela, porque sua função não é escrever algo pessoal, mas institucional, as opiniões foram unânimes no sentido de que isso seria "uma violência intelectual", ${ }^{38}$ ou de que "não se deve obrigar alguém a produzir um voto em dissonância com o seu ponto de vista". ${ }^{39}$

Ao serem questionados se isso não seria um indício de que a opinião pessoal está acima da opinião da instituição, em geral os ministros não entenderam dessa forma. Seja, de um lado, por entenderem que a opinião da instituição não precisa necessariamente ser algo monolítico, como salientou o ministro E: "a soma de mais da metade dos membros faz com que isso seja a instituição"; seja, de outro lado, por entenderem que não existiria algo como uma "opinião da instituição", nem no STF, nem em outros tribunais superiores: "eles não decidem como instituição, eles decidem com os argumentos dos seus ministros, é uma soma de opiniões; o Supremo não vota como instituição". ${ }^{40}$

Para alguns ministros, por fim, a figura do relator para o acórdão é, hoje em dia, absolutamente irrelevante:

\footnotetext{
${ }^{36}$ Neste ponto, é importante ressaltar que a prática do STF, de nomear um relator para o acórdão quando o relator original é vencido, é a mais comum em supremas cortes e tribunais constitucionais.

${ }^{37} \mathrm{O}$ caso mais conhecido é, sem dúvida, o do Tribunal Constitucional alemão.

${ }^{38} \mathrm{H}$.

${ }^{39} \mathrm{E}$.

${ }^{40} \mathrm{G}$.
} 
Isso tinha um significado importante numa época em que não tinha esse sistema de votos individuais, numa época em que o acórdão significava aquilo que o colegiado acordou. Então, obviamente que a redação era a redação dos fundamentos, não era só da ementa. Hoje, o acórdão [...] é o conteúdo dos votos, então ali já tem votos vencidos e votos vencedores. $\mathrm{O}$ relator hoje redige a ementa. ${ }^{41}$

A mesma irrelevância é identificada pelo ministro O: "É apenas a redação da ementa. Só da ementa, porque o restante fica lá, os votos todos"; e pelo ministro Q: "A designação do relator para o acórdão é quase que uma prática cartorária, é só uma questão de saber quem vai escrever a ementa".

Apesar disso, ou, na verdade, em oposição a essa suposta insignificância do relator para o acórdão, são conhecidos os casos de ministros que fazem grande esforço para não serem voto vencido, ainda que haja necessidade de mudar seu voto para seguir a maioria, apenas e tão somente para não perder o posto de relator de um caso importante. Nesse sentido, o ministro R:

No caso Raposa Serra do Sol, o Britto [relator] tinha sido vencido. Quando ele percebeu que o voto do Carlos Alberto Direito era de uma densidade muito grande, ele [alterou sua posição] para ficar como relator, para assinar o acórdão. Para não passar de um para o outro.

\section{CONCLUSÃO}

Ao final das entrevistas com os ministros era proposto um exercício chamado de "criatividade institucional", no qual cada ministro poderia definir aquele que, na sua opinião pessoal, seria o melhor arranjo deliberativo para o STF. ${ }^{42}$ Embora de maneira geral os ministros tenderam a propor modelos deliberativos muito semelhantes ao atual, em um caso específico a maioria dos ministros pareceu preferir um tribunal que tivesse uma regra (ou costume) diverso do atual STF. Para esses ministros, o ministro relator deveria distribuir o seu voto aos outros ministros antes

${ }^{41} \mathrm{D}$.

42 Na definição desse "modelo ideal", os ministros não estavam constrangidos por nenhuma condicionante constitucional, legal ou regimental. Em outras palavras, eles tinham liberdade para criar o modelo que quisessem. 
da sessão de julgamento. Apenas 4 ministros foram contrários a essa prática, que, como explicitado acima, poderia ter um relevante impacto na deliberação no Supremo Tribunal Federal.

Essa mudança provavelmente aproximaria o relator no Supremo Tribunal Federal da imagem que se costuma ter dele, isto é, a de um ministro que tem um papel preponderante no desenvolvimento da deliberação e do processo decisório. De um lado, porque poderia fazer com que o costume de todos os ministros levarem (longos) votos prontos para a sessão de julgamento diminuísse. De outro lado, porque os votos dos ministros - mesmo aqueles redigidos antes da sessão de julgamento - tenderiam a tomar como ponto de partida o voto do relator. A deliberação, portanto, poderia ter um centro e o processo decisório no STF poderia deixar de ser a soma de 11 votos que não dialogam entre si.

Na medida em que quase todos os ministros manifestaram opinião favorável a uma mudança como essa, seria possível supor que existe uma percepção latente segundo a qual, do modo como ocorre hoje, o voto do relator é um voto como outro qualquer e de que isso não é desejável.

\section{REFERÊNCIAS}

DUARTE, G.; FREIRE, D.; MARTINS, R. Revisitando o Supremo Relator: Teorias e Modelos Explicativos. V Seminário Discente do Programa de Pós-Graduação em Ciência Política, 2 de maio de 2015. São Paulo: Faculdade de Filosofia, Letras e Ciências Humanas da Universidade de São Paulo, 2015. Disponível em:

$<$ http://www.sistemas.fflch.usp.br/ocspkp/sdpscp/Vsem/paper/view/402 >. Acesso em: 3 de janeiro de 2016.

GAROUPA, N.; GILI, M.; GÓMEZ-POMAR, F. Political Influence and Career Judges: An Empirical Analysis of Administrative Review by the Spanish Supreme Court. Journal of Empirical Legal Studies, Vol. 9, 4, 2012.

KRANENPOHL, U. Herr des Verfahrens oder nur Einer unter Acht? Der Einfluss des Berichterstatters in der Rechtsprechungspraxis des Bundesverfassungsgerichts. Zeitschrift für Rechtssoziologie, Vol. 30, 2, 
2009.

Hinter dem Schleier des Beratungsgeheimnisses. Wiesbaden:

VS Verlag für Sozialwissenschaften, 2010.

OLIVEIRA, F.L. de. Supremo Relator: processo decisório e mudanças na composição do STF nos governos FHC e Lula. Revista Brasileira de Ciências Sociais, Vol. 27, 80, 2012.

OLIVEIRA, F.L. de. Processo decisório no Supremo Tribunal Federal: coalizões e "panelinhas". Revista de Sociologia e Política, Vol. 20, 44, 2012.

PELLEGRINA, L.D.; GAROUPA, N. Choosing between the government and the regions: An empirical analysis of the Italian constitutional court decisions. European Journal of Political Research, Vol. 52, 4, 2013.

POSNER, R.A. What Do Judges and Justices Maximize? (The Same Thing Everybody Else Does). Supreme Court Economic Review, Vol. 3, $1,1993$.

SILVA, V.A. da. Deciding Without Deliberating. International Journal of Constitutional Law, Vol. 11, 3, 2013.

SPRIGGS II, J.F.; MALTZMAN, F.; WAHLBECK, P.J. Bargaining on the U.S. Supreme Court: Justices' Responses to Majority Opinion Drafts. The Journal of Politics, Vol. 61, 2, 1999.

“Um Voto Qualquer"? O Papel do Ministro Relator na Deliberação no Supremo Tribunal Federal "An Opinion Just Like Any Other"? The Role of the Justice Rapporteur in Deliberation in Brazilian Supreme Court Submetido: 2016-01-06 Aceito: 2016-01-19 